\title{
Sociologia das profissões e percepção de acadêmicos de Odontologia sobre o Agente Comunitário de Saúde em Saúde Bucal
}

\author{
Rodrigo Otávio Moretti-Pires ${ }^{1}$ \\ Levi Abraão Marinho Lima \\ Maria Helena Machado ${ }^{3}$
}

MORETTI-PIRES, R.O.; LIMA, L.A.M.; MACHADO, M.H. Sociology of professions and Dentistry academics' perception about the Community Health Agent in Oral Health.

Interface - Comunic., Saude, Educ., v.15, n.39, p.1085-95, out./dez. 2011.

Professional action in the Family Health Program requires that dentists have an attitude that breaks with traditional clinical practices, such as the articulation with the Agente Comunitário de Saúde (Community Health Agent - ACS) in this context of teamwork. These questions refer to the field of Sociology of Health Professions. This article investigates the perception of Dentistry academics about the ACS performance in oral health work. Concerning the methodology, we used 40 interviews with Dentistry academics from a federal university, and the interviews were treated by a hermeneutical-dialectical process. The results point to lack of training in multiprofessional teamwork, difficulties in working in Public Health, and also lack of knowledge about the tasks of the Family Health Team members, in particular about the ACS's tasks within Oral Health.

Keywords: Medical sociology. Dental students. Family Health. Health manpower. Oral Health.
A atuação profissional no Programa de Saúde da Família exige dos odontólogos uma postura que rompa com práticas clínicas tradicionais, a exemplo da articulação com o ACS neste contexto de trabalho em equipe. Estas questões remetem ao campo da sociologia das profissões de saúde. O presente artigo objetiva investigar a percepção de acadêmicos de Odontologia sobre a atuação dos ACS junto ao trabalho de Saúde Bucal. Em termos metodológicos, foram utilizadas quarenta entrevistas com acadêmicos de Odontologia de uma universidade federal, tratadas por um processo hermenêutico-dialético. Os resultados apontam para a falta de formação no trabalho em equipe multiprofissional, a existência de dificuldades para atuação em Saúde Coletiva, assim como para a deficiência no conhecimento das atribuições dos membros da equipe de Saúde da Família, em especial sobre as atribuições dos ACS junto à Saúde Bucal.

Palavras-chave: Sociologia médica. Estudantes de Odontologia. Saúde da Família. Recursos humanos em saúde. Saúde bucal.
${ }^{1}$ Programa de PósGraduação em Saúde Coletiva, Departamento de Saúde Pública, Centro de Ciências da Saúde, Universidade Federal de Santa Catarina. Campus Universitário, Trindade, Florianópolis, SC, Brasil. 88.040-900. rodrigomoretti@ccs.ufsc.br ${ }^{2}$ Universidade Federal do Amazonas.

${ }^{3}$ Escola Nacional de Saúde Pública. 


\section{Introdução}

A criação do Sistema Único de Saúde (SUS) em 1988 foi um marco inicial e histórico de profundas mudanças no setor da saúde, desencadeando uma reorganização do sistema e de diversos mecanismos, procurando sua implementação de fato no arcabouço dos princípios ideológicos da Universalidade, Equidade e Integralidade.

Na década de 1990, a necessidade de transformação levou à reformulação da atenção primária, processo que estabeleceu o Programa de Saúde da Família (PSF) como estratégia para a consolidação do sistema dentro dos referidos princípios fundamentais.

O PSF traduz avanços no modelo de atenção pela priorização da atenção primária frente à atenção hospitalar ou ao nível especializado. Em termos de processo de trabalho, formaliza, dentro do SUS, a mudança da prioridade na doença e no indivíduo para o foco na saúde e na coletividade - mais particularmente, na família, de forma integral e contínua (Brasil, 2006).

Neste modelo há um caráter diferenciado no processo de trabalho, constituído por equipe multidisciplinar, com ações intersetoriais e participação da população, o que exige novas formas de atuação e postura dos profissionais de saúde inseridos, incluindo os odontólogos (Baldani et al., 2005). Neste ínterim, preconiza-se romper com as práticas tradicionais na assistência, voltadas para processos biológicos, redirecionando o enfoque para o processo de determinação social da saúde (Rabello, Cotbino, 2001). A configuração do trabalho no PSF oferece condições legais para atuação multidisciplinar, capaz de estabelecer conexões entre os conhecimentos de uma profissão e os de outra, com a finalidade de atuação em novas práticas sem excluir a identidade de cada um (Baldani et al., 2005; Moysés, Silveira Filho, 2002; Rabello, Cotbino, 2001).

A pesquisa nacional de amostras por domicílio revelou graves deficiências em termos de Saúde Bucal na população brasileira (Instituto Brasileiro de Geografia e Estatística, 2000), resultando na inclusão da Odontologia entre a equipe mínima do PSF em dezembro de 2000. Em teoria, a inserção da Saúde Bucal no modelo possibilitaria romper com a exclusão não apenas de acesso aos serviços desta natureza, mas também pela lógica do cuidado integral que foge ao curativismo, tecnicismo e biologicismo (Souza, Roncalli, 2007; Calado, 2002).

Mesmo anteriormente à inclusão da Saúde Bucal no PSF, há registros de experiências bem-sucedidas de incorporação do odontólogo no PSF, o que corrobora a importância deste profissional para a saúde integral. No intervalo de dez anos da incorporação (2001-2010), o número de equipes de Saúde Bucal aumentou de 2.248 para 20.103 em todo o país, demonstrando a importância do incentivo do Estado para a consecução da Odontologia neste novo modelo (Brasil, 2010).

Moysés, Moysés e Krüger (2008) defendem que existem problemas críticos para o pleno desenvolvimento do PSF em termos da inserção da Saúde Bucal em seu escopo, sobretudo em relação à deficiência deste modelo em termos práticos, de consonância com seus princípios norteadores, e à falta de qualificação dos odontólogos para o modelo, já que sua formação pauta-se no modelo biomédico.

A inserção do odontólogo no processo de trabalho em Saúde da Família gerou discussões sobre a formação dos profissionais de saúde frente às demandas deste modelo de atenção. A necessidade de se formar um profissional que cuide da Saúde Bucal de acordo com os princípios da Saúde da Família mostrou-se premente, de forma que os Ministérios da Saúde e da Educação têm discutido novas orientações para os currículos de graduação. Essa realidade não se aplica apenas à Odontologia, mas a demais áreas da saúde, em especial a Enfermagem e a Medicina, as três profissões de nível superior que se inserem no PSF atualmente (Moretti-Pires, 2008).

Em particular, um tema imbricado neste contexto é atuação do Agente Comunitário de Saúde (ACS), que exerce funções de grande importância ao estar implicado no contato permanente da equipe com a população e no vínculo com os usuários, sendo, muitas vezes, membros da própria comunidade. Apesar da não-exigência de formação técnica específica, suas principais funções referem-se à identificação de problemas e distúrbios de saúde na população, havendo necessidade de conhecimentos básicos de saúde, articulando o conhecimento geral com saberes específicos de cada área, entre elas a Saúde Bucal (Brasil, 2006). 
Paralelamente, a atuação do ACS diz respeito, também, ao seu papel como educador para a saúde, fortalecendo a capacidade da própria população de enfrentar os problemas de saúde, em um genuíno processo de empoderamento, uma vez que seu processo de trabalho o leva a estar na interface entre comunidade e equipe de saúde (Silva, Trad, 2005; Silva, 2001; Gonzaga, Müller-Neto, 2000).

No entanto, é exíguo o debate sobre o envolvimento do ACS e a equipe de Saúde Bucal (Levy, Matos, Tomita, 2004; Nunes et al., 2002), tema que incide diretamente na efetivação do PSF enquanto modelo de atuação de equipes multiprofissionais de fato (Moretti-Pires, 2008).

Este contexto tem especial interesse para o campo da Sociologia das Profissões de Saúde. Investigações que se refiram às articulações das profissões/ocupações no locus privilegiado da Saúde da Família ainda são exíguas na literatura científica.

Guimarães e Rego (2005) apresentam que o trabalho em equipe é complexo e apresenta consequências importantes para as corporações profissionais da saúde, que se constituem como tal por possuírem características, historicidades e processos de trabalhos que as distinguem das demais. A temática pode tornar-se acirrada e tensa entre as diversas corporações, a exemplo do episódio da regulação do ato médico, no início do século XXI (Pucca, 2006; Guimarães, Rego, 2005; Machado, 2000).

Freidson $(1994,1970)$ afirma que os saberes profissionais e suas especificidades referem-se à autonomia profissional, questão central para o entendimento sociológico das profissões. A existência de conhecimentos próprios à profissão remete ao trabalho especializado e à base epistemológica própria, institucionalmente consagrada. Paralelamente, o PSF exige, no trabalho em equipe, o exercício dos saberes e práticas compartilhadas, com vistas às necessidades do usuário de maneira integral, além das especialidades clínicas.

A atuação em equipe multiprofissional nos moldes do PSF prescreve a articulação entre todas as profissões, criando uma zona comum de troca de conhecimentos, de certa forma na contramão do esoterismo corporativo, termo que descreve a característica do saber exclusivo de cada profissão para Freidson (1970).

Uma vez que os acadêmicos de Odontologia se tornarão os futuros odontólogos, e que estes, pela inserção da categoria no PSF, terão sua atuação na estratégia com seus limites e competências profissionais aplicadas junto às demais profissões/ocupações, o presente trabalho teve por objetivo investigar a percepção dos acadêmicos de Odontologia sobre o papel do ACS frente à atuação em Saúde Bucal, assim como levantar o que é considerado e o que não é considerado como ação privilegiada dos odontólogos no âmbito deste modelo de atenção.

\section{Percurso metodológico}

O presente estudo teve uma abordagem qualitativa, justificando-se que esta permite levantar a percepção e compreensão dos problemas a partir dos próprios sujeitos que os vivenciam (Leopardi, 2002), permitindo a obtenção de informações sobre aspectos específicos de um fenômeno, no que se refere a sua origem e sua razão de ser (Haguette, 2001). Seu maior ganho é, exatamente, a capacidade de incorporar significado e intenção aos atos, às relações e às estruturas sociais, sendo essas últimas tomadas, tanto no seu advento como na sua transformação, como construções humanas significativas (Minayo, 2000). Trata-se de uma metodologia que abarca aspectos da realidade que escapam a simples quantificação e extrapolações, características da ciência positivista (Crotty, 2003). As pesquisas qualitativas indicam a procura essencial pela natureza dos fatos (Berg, 2004).

Com relação ao recrutamento dos sujeitos, após aula regular do curso, o pesquisador explicou o projeto aos acadêmicos do último período, convidando-os a tomarem parte do estudo. Foram entrevistados quarenta acadêmicos de Odontologia, de ambos os sexos, e de uma Instituição de Ensino Superior do Estado do Amazonas, todos do último ano do curso investigado, de um total de 42 universitários.

Em termos instrumentais, utilizou-se a técnica de entrevista individual com roteiro semiestruturado (Minayo, 2000), com questões que versavam sobre a importância e qualificação dos ACS para atuação 
em Saúde Bucal no PSF, o que estes profissionais deveriam saber, e quais as funções dos ACS para com a população adscrita.

Foram critérios de inclusão dos sujeitos: ser discente da Universidade Federal do Amazonas; cursar Odontologia; estar cursando o último período no ano de 2008; cursar todo o curso na mesma turma que os outros sujeitos; não ter cursado outro curso de graduação anteriormente. A inadequação a qualquer dos critérios foi considerada como único critério de exclusão.

Todas as discussões foram registradas por meio de gravação com fita magnética. Todas as gravações foram transcritas na íntegra - material sob o qual se realizou leitura exaustiva para apropriação do conteúdo, seguindo o modelo para tratamento, redução e análise, conforme preconizado pela literatura (Campos, Rodrigues, Moretti-Pires, 2011; Minayo, 2000). A análise pautou-se na hermenêutica dialética (Minayo, 2002), perspectiva adotada pela reflexão que se funda na práxis, na busca pela compreensão atrelada à análise crítica da realidade, processualmente seguindo as etapas de confrontação, convergências e divergências das categorias (Campos, Rodrigues, Moretti-Pires, 2011), registrando a interpretação/dialética e legitimação de falas nos resultados, assim como preconizado no talhe metodológico empregado.

A análise pautou-se no conteúdo da Política Nacional de Atenção Básica (Brasil, 2006), que normatiza o funcionamento do PSF e atribuições profissionais, nas Diretrizes da Política Nacional de Saúde Bucal (Brasil, 2004); em literatura especializada em Saúde Coletiva (Moretti-Pires et al., 2007; Baldani et al., 2005; Lima, Moura, 2005; Levy, Matos, Tomita, 2004; Calado, 2002); e nos pressupostos da Sociologia das Profissões (Machado, 2000; Machado, 1995; Freidson, 1994; 1970), utilizando-se uma perspectiva hermenêutico-dialética (Minayo, 2002).

O presente trabalho foi aprovado pelo Comitê de Ética em Pesquisa com Seres Humanos da Universidade Federal do Amazonas (CEP/UFAM), obedecendo todos os procedimentos preconizados na legislação brasileira sobre pesquisa com seres humanos.

\section{Resultados}

Os acadêmicos entrevistados, de uma maneira geral, apresentaram certa noção básica do que é (ou o que deveria ser) um ACS, em perspectiva consonante com as diretrizes do PSF. Atribuem ao ACS a responsabilidade pela atenção primária da população assistida. No que concerne especificamente à Saúde Bucal, os ACS têm atuação frente aos cuidados da higiene oral, técnicas adequadas de escovação, prevenção e diagnósticos de problemas simples, além do papel de educador para saúde bucal.

"O ACS deve saber sobre higiene bocal, hábitos alimentares saudáveis para a dentição, fatores que influencie no processo da cárie, [...] Instrução de higiene oral, orientação..., técnicas de escovação e higiene, para instruir as pessoas que são visitadas". (entrevistado 22)

"O AC deve primeiramente saber ensinar a seus pacientes, técnicas adequadas de uma boa higiene bucal. Deve saber passar para as pessoas como deve ser usado o fio-dental, como deve ser feita a limpeza bucal, quais os produtos devem ser utilizados". (entrevistado 13)

A concepção de que o ACS tem importância emergiu. No entanto, para estes futuros odontólogos, aqueles que atualmente desempenham a função não estão devidamente capacitados para exercerem ações em Saúde Bucal, justificando tal percepção pela falta de orientação quanto à problemática, falta de recursos e falta de disponibilidade de tempo para este exercício.

"Os ACS devem ser qualificados para desempenharem a função. Com certeza deveriam saber muito mais coisas do que já sabem. É muito complicado o PSF funcionar com agentes ignorantes, pois eles não conseguem passar para o restante da equipe o que realmente ocorre na comunidade". (entrevistado 03) 
"Não poderiam ter uma maior efetividade, pela pouca disponibilidade de material e tempo". (entrevistado 37)

“Deveria saber quais cuidados tomar, com a finalidade de todos terem saúde bucal e não terem cáries. Eles não estão preparados para isso". (entrevistado 01)

Para parte dos entrevistados, os ACS deveriam ter melhor qualificação para o trabalho, no sentido de que fossem capazes de realizar funções que não se constituem pertinentes legalmente aos ACS, com a justificativa de diminuição das filas nos hospitais, melhor atendimento aos pacientes e auxílio aos odontólogos. Estas afirmações mostram indício da falta de formação destes futuros odontólogos para a Saúde da Família, uma vez que desconhecer a importância de cada profissional em sua especificidade, de maneira articulada com as demais profissões, torna-se uma questão grave quando se pensa na inserção destes futuros profissionais no PSF.

"O ACS deve saber tudo, conhecimento nunca é demais. Deveriam fazer exames mais complexos, com mais dedicação aos estudos científicos". (entrevistado 07)

"Precisam ter noção sobre Lesões orais, com relações sistêmicas, noções de lesões précancerigenas, técnicas de escovação, noções de cronologia eruptiva dental". (entrevistado 19)

“Deveriam saber fazer um tratamento demasiadamente sofisticado como: canal, clareamento, ou limpezas muito elaboradas [...]. Porém não podem por falta de tempo e recurso, para que eles também aprendam". (entrevistado 21)

"Acho que o ACS deveria ter pelo menos curso superior, ou entender sobre saúde". (entrevistado 22)

Parte dos estudantes aponta que a dificuldade dos ACS em exercer corretamente suas funções está relacionada à falta de conhecimento sobre as diretrizes do PSF. No entanto, não apontam como ou quais seriam os tópicos a serem abordados para uma capacitação desta natureza.

“Deveria saber primeiramente a importância do PSF, as metas deste programa e o papel do ACS". (entrevistado 10)

“Devem saber relacionar a Odontologia com outras áreas da saúde para que realmente o PSF funcione". (entrevistado 33)

Os acadêmicos revelam falta de conhecimento apropriado sobre os princípios e processo de trabalho no PSF, em termos específicos da Odontologia, e os saberes e práticas a compartilhar com os demais profissionais, entre eles o ACS. Tal situação pode ser associada à grande carga de conhecimentos técnicos específicos da formação profissional, altamente biologicista. Ao debater o tema 'saúde', os futuros odontólogos apresentam dificuldades em analisar as outras categorias profissionais em paralelo às suas funções, o que denuncia, no mínimo, falta de informação e vivência multiprofissional e junto ao processo de trabalho em Saúde da Família.

Em um talhe oriundo de modelo de ação odontológica, que segmenta prevenção e cura, os entrevistados responderam que a atuação dos ACS junto à Saúde Bucal se refere às ações preventivas e educativas, não só com visitas domiciliares, mas também em palestras e acompanhamento/detecção de problemas bucais com imediato encaminhamento a unidade de Saúde da Família, para os cuidados pelos odontólogos. Há total desconsideração sobre a possibilidade de trabalho conjunto, ou que extrapole o limite de protocolos, ou, mesmo, da Educação para a Saúde como ações de cunho diferente de palestras. O ACS não é percebido como um profissional a serviço do empoderamento, sendo aludido como um recurso humano a serviço da vigilância em saúde, mas não da promoção em saúde. 
"O ACS tem que saber fazer prevenção e curativos, e saber encaminhar casos mais graves para centros especializados". (entrevistado 03)

"Ele deve prevenir o aparecimento e o aumento do numero de cáries na população". (entrevistado 09)

"Trabalhar na prevenção e informação da população sobre a prevenção da placa bacteriana e prevenção de doenças". (entrevistado 19)

"Ele deve levar panfletos sobre o controle de câncer bucal e poderia se instruído por um cd a levar informações e ensinar os pacientes a fazer curto exame. Se constatar alguma alteração tecidual, procurar um dentista com ajuda do agente". (entrevistado 40)

\section{Discussão}

Com a criação e implementação do PSF no Brasil, houve mudança significativa na necessidade de profissionais preparados para o trabalho no novo talhe da Atenção Primária, desencadeando a discussão sobre mudanças na constituição das equipes de saúde, incluindo profissões tradicionalmente liberais como a Odontologia. Estas discussões não se referiram apenas a este aspecto de interesse ao sistema de saúde, mas também ao anseio das corporações por novos postos, uma vez que existem alterações no mundo do capital como um todo neste período, que afetaram diretamente o locus privilegiado de atuação profissional (Guimarães, 2005), em particular no mundo do trabalho dos odontólogos (MorettiPires, 2005).

Em uma aproximação da história da Odontologia com a Medicina no Brasil, fica claro que a oferta de serviços médicos ao sistema público diferiu significativamente quando comparado à inserção da Odontologia, na medida em que esta procura o setor público quando a remuneração oriunda dos consultórios particulares não é mais satisfatória. Tal fato é creditado à crise do mercado de trabalho da Odontologia a partir da década de 1980 (Moretti-Pires, 2005).

Diferente da categoria médica, em que existe prestação de serviços particulares conveniados junto ao SUS pelo princípio da complementaridade do setor privado, a categoria dos odontólogos tem a venda de seus serviços exclusivamente de forma assalariada (Souza, Roncalli, 2007).

As crescentes dificuldades de um mercado de trabalho imerso no processo de reestruturação produtiva do capital, acrescidas à remuneração garantida pelo trabalho no serviço público, além da nãodependência do pagamento dos pacientes, fazem do setor uma oportunidade ansiada pelas categorias não médicas de saúde, que batalham pela sua inserção no trabalho de Saúde da Família.

De maneira diferente de outras corporações profissionais - como os fisioterapeutas, os nutricionistas, os assistentes sociais - a inserção do odontólogo no PSF foi vitoriosa, fundamentada nas necessidades da população com relação à Saúde Bucal (Pucca, 2006), através do já referido levantamento epidemiológico nacional que denunciou a demanda por ações curativas odontológicas para a maioria dos brasileiros.

Uma vez que a proposta do PSF se pauta não apenas na ação curativa, mas sim em uma visão ampliada de Saúde, rapidamente questionou-se a formação do odontólogo, na medida em que se distancia desta perspectiva. A promoção de saúde é um dos baluartes que sustentam este modelo de atenção, sendo que o odontólogo é formado para a prática clínica em consultório particular, para o trabalho individual sobre o paciente, perfil dicotômico ao trabalho em PSF (Moretti-Pires, 2008, 2005).

Os odontólogos buscam inserção em Saúde da Família como forma de resistência às mudanças no mundo do trabalho e à perda das características liberais da profissão, mesmo sem a capacitação para o trabalho em equipe de saúde e a articulação com outros setores. Vale ressaltar que os acadêmicos investigados cursam faculdade que segue formalmente as Diretrizes Nacionais Curriculares para os Cursos de Odontologia, que orientam a formação do odontólogo para o trabalho no SUS (Moretti-Pires, 2008). 
Guimarães e Rego (2005) defendem que, para efetividade do trabalho multiprofissional, faz-se necessária a reavaliação dos saberes e competências específicas de cada formação, preservando limites e respeitando a divisão do trabalho, mas não desconsiderando a necessidade de ações em comum, remetendo a questionamentos, tais como: quais competências diferenciam-se entre as tradicionais e as da Saúde da Família? Para quais profissões/ocupações?

No caso específico do presente trabalho, a inserção da Odontologia no PSF já é uma realidade concreta, inclusive com debates na literatura sobre a adequação, entre o ensino universitário, em formar para o SUS/PSF (Ciffo, Ribeiro, 2008). No entanto, o mesmo não pode ser afirmado com relação aos estudos sobre profissionalização e outras temáticas próprias da Sociologia das Profissões.

Na medida em que o monopólio de saberes, como exposto, é um requisito para a profissionalização, transmitida de quem a possui para os futuros pares, debate-se: na proposta da ação profissional em Saúde da Família, a equipe multiprofissional fere o princípio dos monopólios específicos de cada profissão?

Ao se questionar qual o papel do ACS frente à Saúde Bucal, os futuros profissionais transitaram entre uma perspectiva de desconhecimento do que esta ocupação poderia desempenhar até um claro desconhecimento sobre os limites profissionais da atividade da Odontologia, uma vez que diversas das atividades atribuídas aos ACS são próprias da identidade profissional do odontólogo.

Pereira e Pereira Neto (2003) reafirmam a perspectiva de que uma das etapas da profissionalização repousa no valor social de determinada profissão. Uma abordagem muito adequada para o modelo de atuação em Saúde da Família, vez que fulgura, entre suas diretrizes, o imergir da equipe na realidade em que a população encontra-se. A equipe tem ampla possibilidade de mostrar e firmar seu valor social para a população.

Mas em que estes princípios referem-se ao processo de construção profissional na academia? Em que medida o odontólogo, objeto do presente estudo, aprende estas competências que seriam de todos os que atuam em Saúde da Família e não apenas dele? Esta dimensão deve fazer parte da formação do odontólogo? Mas, profissionalizar não é legar um conhecimento específico e de monopólio corporativo?

As sociedades atuais desenvolveram o pensamento de que o profissional não é apenas um indivíduo capaz de resolver problemas concretos relacionados aos problemas do cotidiano da população, mas também um indivíduo detentor de conhecimento que lhe proporciona um poder de autorregulamentação, considerado uma das maiores ambições das profissões atuais, proporcionando, à profissão, a capacidade de delimitar os próprios limites de atuação (Souza, Roncalli, 2007).

No caso específico do modelo de Saúde da Família, o interesse do Estado e da sociedade supera o interesse específico das corporações. Há indícios de que os cursos universitários não conseguiram, até o presente, adequação a esta realidade, preservando o talhe tradicional. Ao mesmo tempo, há constantes iniciativas do Estado para a migração da formação que prima pela especialidade para outra que se torne fortemente pautada na generalidade, a exemplo do Pró-Saúde (Brasil, 2005).

Reafirma-se que o debate contemporâneo sobre as profissões de saúde e sua articulação no SUS não se refere apenas a mudanças internas nas universidades e nos modelos pedagógicos. Antes, diz respeito ao processo de formação e desenvolvimento da divisão social do trabalho em saúde que,

historicamente, consolidou-se na especialização e monopólio do saber.

Para Machado (1995), os conhecimentos ímpares e a existência de trabalho próprio que não pode ser desempenhado por mais nenhum outro tornam a Medicina e a Odontologia profissões em termos sociológicos, havendo clientela específica para sua negociação profissional. As características do SUS vão à contramão do trabalho em saúde especializado, primando pela promoção de saúde conduzida por generalistas. Generalistas em equipes multiprofissionais que foquem na Saúde da Família e no entorno sociocultural dos pacientes, exigindo uma formação e profissionalização diferenciada da tradicional, conforme Moretti-Pires (2008).

No que concerne ao presente estudo, os entrevistados dão a impressão de fundamentarem suas respostas a partir da experiência do dia a dia como usuário do sistema de saúde, a despeito das disciplinas relativas à saúde pública. Ao se referirem ao trabalho neste setor, a maior preocupação diz respeito à orientação sobre saúde bucal para a população, como medida de ação junto à coletividade, 
também revelando silêncio sobre outras formas de atuação. Esta falta de perspectiva sobre possibilidades de atuação não tradicional segue paralela ao conceito de que os ACS deveriam ter noções de procedimentos odontológicos mais complexos, o que vai ao encontro de um paradoxo: na compreensão destes futuros odontólogos, quais os limites da atuação multiprofissional em termos operacionais? Até que momento ou em que o odontólogo e o ACS compartilham o mesmo objeto no processo de trabalho? As especificidades do trabalho odontológico, assim como a articulação que será exigida em PSF e no SUS, foram discutidas com estes acadêmicos no processo de formação profissional? Quais são as especificidades processuais e tradicionais de cada categoria profissional que devem ser respeitadas nesta nova forma de organização do trabalho?

Na medida em que os ACS são trabalhadores selecionados a partir do capital social que dispõem, facilitam a interface entre os demais profissionais de Saúde da Família e a sociedade em que se inserem. A capacitação destes profissionais, portanto, é de suma importância para se atingirem os objetivos do programa, que parte de uma lógica de planejamento embasado na realidade dos que vivem os problemas de saúde, incluindo, nestes, os pertinentes à Saúde Bucal (Lima, Moura, 2005).

Apesar de os depoimentos revelarem este conteúdo, não operacionalizam quais seriam os saberes e as práticas gerais, o que também não está claro nos documentos oficiais utilizados como fundamento da análise dos resultados (Brasil, 2006, 2004).

Há evidencias empíricas de que a capacitação dos profissionais do PSF para o trabalho em conjunto em saúde bucal é deficiente, inclusive com problemas quanto ao envolvimento das comunidades e à avaliação da efetividade/eficácia de ações de saúde bucal realizadas (Moretti-Pires et al., 2007). Ainda se preserva o enfoque tradicionalista e segmentário. Levantam-se outras questões: qual é o corpo de conhecimento multiprofissional? Qual é o corpo de conhecimentos da equipe de PSF além da sobreposição de conhecimentos específicos das corporações?

Em especial para a Odontologia, o PSF tem se tornado uma importante instância da inserção do odontólogo recém-formado no mercado do trabalho. Paralelamente, a expansão do número de odontólogos na atenção primária está calcada, na perspectiva do programa, como importante estratégia de reorientação assistencial, não apenas na expansão quantitativa de serviços, mas qualitativa em termos de transformar o SUS, de fato, em profunda coerência com seus princípios norteadores.

O presente estudo limitou-se a investigar a percepção dos acadêmicos de Odontologia sobre questões eminentes da Sociologia das Profissões no âmbito da prática profissional em Saúde da Família, dada sua característica que incide no paradoxo entre a formação profissional em saberes privilegiados à corporação odontológica e a atuação em equipe multiprofissional, tomando a articulação do odontólogo com o ACS como emblema de análise.

Há que se ressaltar a necessidade de estudos pela perspectiva sociológica empregada, que abordem alguns limites do presente trabalho, tais como: a diferença entre os achados e a articulação da Odontologia no PSF na percepção dos ACS, assim como dos próprios odontólogos que atuam no modelo de atenção. Outra limitação que incita a investigação posterior é a importância da Saúde Pública nos cursos de Odontologia - responsáveis pela profissionalização; da mesma forma que a motivação para o trabalho em Saúde da Família.

\section{Considerações finais}

Os dados empíricos reafirmam o debate na literatura científica sobre a necessidade de se criarem mecanismos de capacitação permanente às equipes de Saúde da Família. Tal capacitação deverá estar articulada desde o ensino de graduação, uma vez que, neste espaço, se desenvolvem as competências específicas que mediarão futuras ações dos profissionais de saúde.

Por outro lado, odontólogos e os ACS estão próximos dentro das equipes de PSF. Próximos fisicamente. Próximos em termos de objetivos comuns frente às demandas populacionais. Próximos em termos de possibilidades de atuação. No entanto, distantes na prática diuturna, um impulso que originou a presente investigação. Os dados empíricos do presente estudo evidenciam a ausência de instrumentos curriculares que permitam que vivenciem esta proximidade de áreas, não apenas em vistas à questão de 
efetivar o trabalho em equipe como um fato, mas também pela necessidade em termos de saúde bucal que as populações apresentam. A capacitação dos ACS nesta área, mesmo na forma de orientação teórica, como no preparo para a identificação de problemas que necessitem intervenção odontológica, é um encaminhamento necessário para o verdadeiro entrosamento entre esta categoria e as categorias odontológicas, sejam estas odontólogos, técnicos de saúde bucal ou atendentes de saúde bucal.

No entanto, o debate deve caminhar, também, para a questão das competências e dos limites de cada profissão/ocupação em Saúde da Família, para a existência do objeto e processo de trabalho que efetive a Equipe enquanto tal, não apenas como a ação conjunta de diversas corporações no mesmo paciente.

O presente trabalho traz considerações sobre a problemática no contexto do ensino odontológico. Fica a necessidade de investigação junto aos próprios ACS, assim como junto às demais categorias odontológicas, havendo lacunas a serem investigadas por outros trabalhos na temática à luz da Sociologia das Profissões.

\section{Colaboradores}

Os autores trabalharam juntos em todas as etapas de produção do manuscrito.

\section{Referências}

BALDANI, M.H. et al. A inclusão da Odontologia no Programa Saúde da Família no estado do Paraná, Brasil. Cad. Saude Publica, v.21, n.4, p.1026-35, 2005.

BERG, B.L. Qualitative research methods for the Social Sciences. Long Beach: Pearson, 2004.

BRASIL. Ministério da Saúde. Departamento de Atenção Básica. Atenção Básica e Saúde da Família. Disponível em: <http://dab.saude.gov.br/dab/ abnumeros.php\#historico>. Acesso em: 20 nov. 2010.

. Ministério da Saúde. Portaria n 648, de 28 de março de 2006. Aprova Política Nacional de Atenção Básica, estabelecendo a revisão de diretrizes e normas para a organização da Atenção Básica para o Programa Saúde da Família (PSF) e o Programa Agentes Comunitários de Saúde (PACS). Brasília: Ministério da Saúde, 2006.

Ministério da Educação. Ministério da Saúde. Portaria n².101, de 3 de novembro de 2005. Dispõe sobre o Programa Nacional de Reorientação da Formação Profissional em Saúde (Pró-Saúde) para os cursos de graduação em Medicina, Enfermagem e Odontologia. Brasília: Ministério da Educação/Ministério da Saúde, 2005

Ministério da Saúde. Secretaria de Atenção à Saúde. Departamento de Atenção Básica, Coordenação de Saúde Bucal. Diretrizes da Política Nacional de Saúde Bucal. Brasília: Ministério da Saúde, 2004.

CALADO, G.S. A inserção da equipe de saúde bucal no Programa de Saúde da Família: principais avanços e desafios. 2002. Dissertação (Mestrado) - Escola Nacional de Saúde Pública, Fundação Oswaldo Cruz, Rio de Janeiro. 2002.

CAMPOS, D.A.; RODRIGUES, J.; MORETTI-PIRES, R.O. Pesquisa qualitativa em Saúde Coletiva como instrumento de transformação social: uma proposta metodológica fundamentada na postura hermenêutica-dialética. Saude Transf. Soc., v.1, n.3, 2011. (no prelo)

CIUFFO, R.S.; RIBEIRO, V.M.B. Sistema Único de Saúde e a formação dos médicos: um diálogo possível? Interface - Comunic., Saude, Educ., v.12, n.24, p.125-40, 2008.

CROTTY, M. The Foundations of social research. London: Sage Publications, 2003. 
FREIDSON, E. Professionalism reborn: theory, prophecy and policy. Cambridge: Polity Press, 1994.

Professional dominance. Chicago: Aldine, 1970.

GONZAGA, A.A.; MÜLLER-NETO, J.S. Usuários avaliam as equipes de Saúde da Família em Mato Grosso. Rev. Bras. Saude Família, v.1, n.3, p.53-6, 2000.

GUIMARÃES, R.G.; REGO, S. Perspectivas teóricas sobre Medicina e profissão médica: uma proposta de enfoque Antropológico. Cienc. Saude Colet., v.10, n.esp., p.7-17, 2005.

HAGUETTE, T.M.F. Metodologias qualitativas na Sociologia. Petrópolis: Vozes, 2001.

INSTITUTO BRASILEIRO DE GEOGRAFIA E ESTATÍSTICA. Acesso e utilização dos serviços de saúde: PNAD 1998. Rio de Janeiro: IBGE, 2000.

LEOPARDI, M.T. Metodologia da pesquisa na Saúde. Florianópolis: UFSC, 2002.

LEVY, F.M.; MATOS, P.E.S.; TOMITA, N.E. Programa de Agentes Comunitários de Saúde: a percepção de usuários e trabalhadores da saúde. Cad. Saude Publica, v.20, n.1, p.197-203, 2004.

LIMA, J.C.; MOURA, M.C. Trabalho atípico e capital social: os agentes comunitários de saúde na Paraíba. Soc. Estado, v.20, n.1, p.103-33, 2005.

MACHADO, M.H. Médicos, organizações de saúde e ética. Rev. Bras. Educ. Med., v.24, n.1, p.68-71, 2000

Sociologia das profissões: uma contribuição ao debate teórico. In: $\overline{(\mathrm{Org}) .}$ Profissões de saúde: uma abordagem sociológica. Rio de Janeiro: Fiocruz, 1995. p.13-33.

MINAYO, M.C.S. Hermenêutica-dialética como caminho do pensamento social. In: MINAYO, M.C.S.; DESLANDES, S.F. (Orgs.). Caminhos do pensamento: epistemologia e método. Rio de Janeiro: Fiocruz, 2002. p.42-55.

O desafio do conhecimento: pesquisa qualitativa em saúde. São Paulo: Hucitec-Abrasco, 2000.

MORETTI-PIRES, R.O. O pensamento crítico-social de Paulo Freire sobre humanização e o contexto da formação do enfermeiro, do médico e do odontólogo. 2008. Tese (Doutorado) - Escola de Enfermagem de Ribeirão Preto, Universidade de São Paulo, Ribeirão Preto. 2008.

A mercantilização da saúde: o trabalho dos cirurgiões dentistas em um contexto de mudanças - estudo com cirurgiões dentistas assalariados do município de Ribeirão Preto (SP). 2005. Dissertação (Mestrado) - Faculdade de Medicina de Ribeirão Preto, Universidade de São Paulo, Ribeirão Preto. 2005.

MORETTI-PIRES, R.O. et al. O conhecimento dos agentes comunitários sobre saúde bucal: uma perspectiva sobre deficiências em educação em saúde no PSF. Cienc. Cuid. Saude, v.6, n.3, p.325-34, 2007.

MOYSÉS, S.T.; MOYSÉS, S.J.; KRÜGER, L. Saúde bucal das famílias: trabalhando com evidências. São Paulo: Artes Médicas, 2008.

MOYSÉS, S.J.; SILVEIRA FILHO, A.D. Saúde bucal da família: quando o corpo ganha uma boca. In: SILVEIRA, A.D. et al. (Orgs.). Os dizeres da boca em Curitiba: boca maldita, boqueirão, bocas saudáveis. Rio de janeiro: Centro Brasileiro de Estudos da Saúde, 2002. p.133-61.

NUNES, M.O. et al. O Agente Comunitário de Saúde: construção da identidade desse personagem híbrido e polifônico. Cad. Saude Publica, v.18, n.6, p.1639-46, 2002. 
PEREIRA, F.M.; PEREIRA NETO, A. O psicólogo no Brasil: notas sobre seu processo de profissionalização. Psicol. Estud., v.8, n.2, p.19-27, 2003.

PUCCA, G.A. A política nacional de Saúde Bucal como demanda social. Cienc. Saude Colet., v.11, n.1, p.243-6, 2006.

RABELLO, S.B.; COTBINO, M.P.F. A Inserção do CD no Programa Saúde da Família. Rev. Bras. Odontol., v.58, n.6, p.266-7, 2001.

SILVA, I.Z.Q.J.; TRAD, L.A.B. O trabalho em equipe no PSF: investigando a articulação técnica e a interação entre os profissionais. Interface - Comunic., Saude, Educ., v.9, n.16, p.25-38, 2005.

SILVA, J.A. O Agente Comunitário de Saúde do Projeto Qualis: agente institucional ou agente da comunidade? 2001. Tese (Doutorado) - Faculdade de Saúde Pública, Universidade de São Paulo, São Paulo. 2001.

SOUZA, T.M.S.; RONCALLI, A.G. Saúde bucal no Programa Saúde da Família: uma avaliação do modelo assistencial. Cad. Saude Publica, v.23, n.11, p.2727-39, 2007.

MORETTI-PIRES, R.O.; LIMA, L.A.M.; MACHADO, M.H. Sociología de las profesiones y percepción de académicos de Odontologia sobre los Agentes Comunitarios de Salud en la Salud Bucal. Interface - Comunic., Saude, Educ., v.15, n.39, p.1085-95, out./dez. 2011.

La actuación profesional en el Programa de Salud Familiar exige a los dentistas una actitud capaz de romper con las prácticas tradicionales de clínicos, tales como la articulación dentro de la ACS en este contexto de trabajo en equipo. Estas cuestiones se refieren a la sociología de las profesiones de salud. En este artículo se investiga la percepción de académicos de Odontología sobre el desempeño de los ACS en el trabajo de salud oral. En términos metodológicos, se utilizaron 40 entrevistas con académicos de Odontología de una universidad federal, tratadas por un proceso hermenéutico-dialéctico. Los resultados apuntan a la falta de formación en el trabajo en equipo multiprofesional, las dificultades en el rendimiento de la Salud Colectiva, tales como la deficiencia de los conocimientos sobre las atribuciones de los miembros del equipo de Salud de la Familia, en especial sobre las tareas de lo ACS dentro de la salud oral.

Palabras clave: Sociología médica. Estudiantes de Odontologia. Salud de la Família. Recursos humanos en salud. Salud bucal. 